And when the time comes for $\mathrm{Mr} L$ to breathe his last, I can remember him fondly, and remember all that I have learned from our brief interaction.

And I will continue to push this trolley, and collect blood results hurriedly lest the consultant should get annoyed. I will continue to avoid being asked complicated medical questions by him, especially when he is in a bad mood. And with the arrival of the next abnormal blood results, and the breaking of bad news that will follow, I will remember that my role is not to offer sympathy for the suffering of a patient filled with fear, or try to fill awkward silences, but to participate in the relieving of a suffering which is ours, as together, and relentlessly, we move towards the finish line.

\section{Majid Rehman Khan}

DOI: 10.3399/bjgp09X472764

\title{
Occupational health specialists in primary care: up-to-date with changing times?
}

Primary care practitioners need to be unified, collaborating to continually improve access to care for all our patients, while maintaining our own traditions of expertise.

The Health, Work and Wellbeing agenda $^{1}$ set by Dame Carol Black in 2005 aims to guide the jobless into sustained employment while also maintaining the health of those currently in employment. How can we provide the occupational health expertise required to support and develop this agenda, locally? I propose the idea of occupational health practitioners joining forces with other specialist services within the fledging GPled health centres. ${ }^{2}$ By providing services centrally they could then become a resource for all GPs within the primary care trust area.

These versatile occupational health practitioners offer a broad knowledge base of employee welfare, occupations, and health and safety law. We already support many patients as employees returning to the working environment, whether their conditions were acute or causing them chronic ill health. We are used to negotiating with employers, unions, human resources, and safety personnel, for patients' planned and safe return to work.

With the inclusion of occupational health practitioners in GP-led health centres, there could be numerous advantages that would certainly add value to the phrase 'collaborative working'. One could push the boundaries further and suggest including representatives of the Department of Work and Pensions, who could visit regularly to review case conferences where individuals have complex support needs for their employment.

The occupational health professional skill set involves the following:
- work place risk assessments/advice (for new and expectant mothers in all occupations, lone workers, and those that work in confined spaces);

- sickness absence referrals (short and long term);

- first-line counselling (some of us have first-line CBT training and have developed sessions concerning stress awareness);

- fork lift truck medicals:

- ability to negotiate and navigate through complicated case histories;

- respiratory health surveillance (to include spirometry);

- skin health surveillance (to include latex screening);

- audiometric health surveillance (to include audiometry);

- hand-arm vibration screening;

- night worker health assessments;

- pre-employment health assessments;

- executive medicals;

- first aid at work training/advice; and

- manual handling training/advice.

Let us build a health economy in the community of specialist skills and maybe our innovation will fend off unwanted enforcement as to how we should meet the government targets.

\section{Marie Hickinbotham}

\section{REFERENCES}

1. Department of Health.

healthworkwellbeing.http://www.workingforhealth.go v.uk/Default.aspx (accessed 8 Sep 2009).

2. Professor Field S. RCGP response to NHS Next Stage review (press release).

http://www.rcgp.org.uk/news_and_events/news_roo $\mathrm{m} / \mathrm{rcgp}$ _news_stories/nhs_next_stage_review.aspx (accessed 8 Sep 2009).

DOI: 10.3399/bjgp09X472773 